\title{
Gold the Chemical Unknown
}

\section{A THING OF BEAUTY IN NEED OF EXPLORATION}

\section{W. D. Mogerman}

The chemical durability of gold, on which its physical attractiveness so largely depends, was appreciated by some of the earliest races of mankind. One can see this in many museum artifacts known to be more than 3,000 years old and still as beautiful as ever. The poetic mind does not normally probe such a perpetual joy, but only seeks to find more of it. To this day, a strong tendency has persistedespecially among non-miners- to envisage gold finds in convenient bulk form and to seek them in distant places. As we shall see, that age-old tendency has recently been confirmed by several very long journeys indeed, made by bold travellers who carried much more gold in their gear than they found on arrival.

One of the first and most important attractions in any new-found territory has always been its mineral supply; but no expedition was ever sent forth to discover the uneconomic silicon, aluminium and iron materials that are everywhere underfoot at home. Accordingly, although it has not been loudly bruited about, the rock samples so laboriously imported from the moon by American astronauts have disappointed many officials, as well as millions of ordinary taxpayers who can gaze at television for hours and still remain unmoved by the vast importance of cosmological dating to them. Vanished are all wild dreams of seeing the exploits of Hawkins and Drake repeated before their eyes. The latest lunar loot turns out to display a number of minor esoteric differences from the terrestrial and meteoric rocks that have been known for many centuries, but on major points of chemical composition it agrees very closely with the dullest of conventional domestic samples. By and large, the moon's surface rocks are apparently composed of the cheap and common elements that make up most of the earth's crust; and although they are said to be much older they do not seem to be demonstrably wiser. Dr. Samuel Johnson could kick a lunar rock as well as any other to prove his point about reality.

The terrestrial abundance of gold is given as 0.005 parts per million by weight. That's low enough, but in the lunar samples seen so far gold cannot even be detected by the most sensitive spectrographic means. (And the platinum group fares just as badly out there.) This is poverty indeed, even below the accepted figure for the cosmic abundance of gold, given as 0.145 when the presence of silicon is taken as 1 million. Although it is probably still too early to declare the moon an effective mineralogical poorhouse, it seems clear enough that her contributions will never restore anyone's balance of international payments.

Thus the unique yellow element remains a scarce commodity everywhere, though always plentifully associated with weird views and deeds. If one considers technical factors only-and omits the chemical reactions connected with extractive mining operations-it is likely that the term "precious metal" has adversely affected the chemistry of gold much more than its metallurgy. Perhaps its metallurgy has not been affected at all. Once the shining metal has been won from the earth, its solid mechanical and physical properties become fair and essential game for all investigators; and the resulting scrap, if any damage is done to test specimens, remains perfectly visible and readily remeltable without perceptible loss. Chemical investigations, on the other hand, have long suffered from a psychological ban imposed ages ago. Preliminary dissolution and temporary disappearance constitute a serious step, one that frightened many early investigators and current teachers on a budget, men who never hesitated to sacrifice other metals for beneficial study. Its a step that still makes many modern research directors unnecessarily nervous.

Of course, it was probably Methuselah who first found during his extensive career that the common metals were always easier to dissolve, but the extraordinary stability of gold was not the main factor that kept its chemistry from being developed during the long centuries that passed while the reactions and compounds of other metals were being fruitfully studied. An incorrect or untimely hypothesis can present just as firm a barrier to progress as a very resistant material. During the long period of alchemical dominance, gold was awesomely looked upon as "The Ultimate Metal"-perfect and complete, not to be improved by study but to be created or multiplied by accelerated means. An incorrect hypothesis is not necessarily without some value, when sincerely followed up. But in any sincere effort to transmute, gold itself was not involved. It was the common elements that were relentlessly tortured and examined for any gradual 
"The Sceptical Chymist" in one of his more than usually sceptical moods. Robert Boyle, writing in 1661, expresse himself forcibly on "the wasting of materials that are somewhat too precious and costly upon so groundless adventures of which not only the success is doubtful but the very possibility is not yet demonstrated"

improvement, and thus a great deal was indirectly learned about them and their ways. Some of the more honest and gifted would-be gold-makers even turned up new elements.

The vain effort to transmute the common elements may have been helpful, but it could not lead to much knowledge of gold and its reactions, since they were not consulted. A very notable example may be of interest here. In the year 1675, young Isaac Newton was encouraged by a private hint from Robert Boyle to work on a hypothesis that "a certain kind of mercury" could be readily changed into pure gold. "The fingers of many will itch to be at the knowledge of such a mercury", wrote Newton to a friend. "The Sceptical Chymist" was not sceptical about that. Boyle was so thoroughly convinced that he had already accomplished the feat in a small way, that he finally persuaded the English government (1689) to repeal the old law prohibiting gold multiplication that had been on the books since the time of King Henry VI. Obviously, nothing could be said about such a matter in public.

Newton agreed that gold-making in the wrong hands would clearly be against public policy, especially after he became Master of The Mint. But he need not have worried. Although Boyle and Newton laboured on this problem for many years, neither man produced even the most private communications on this subject, and the general public remained calm. If these brilliant men had studied gold itself with such persistent industry, there surely would have been a great deal to publish, and with no need for secrecy. One may contrast this debacle with Newton's enormous success on behalf of another hypothesis, the one dealing with the corpuscular theory of light. This time he applied his genius to the desideratum light itself, and felt free to publish all that he had learned. The resulting book, "Opticks", changed the course of science and is still regarded as one of the greatest classics of investigation.

One may produce a handy moral here about the timeliness of hypotheses. After Newton died, corpuscles of light and transmutation of metals entered upon a period of disfavour that lasted many decades,
But for the Salt of Gold, Inever could either fee it, or be farisfied that there was ever fuch a thing feparateed, in rerum natura, by the telation of any credible eye witneffe. And for the feveral Procelfes that Promife that effeet, the materials that mutt be wroughs upon are lomewhat too pretious and coftly to be wafted upon fo groundleffe adventures, of which not only the fucceffe is doubrful, but the very poffibility is not yet demonttrated. Yer that which moft deterres me from fuch tryalls, is not their chargeablenefle, but their unfatisfactorineffe, though they fhould fucceed. For the Exrraction of this golden Salt being in Chymilts Proceffes prefribed to be effected by corrofive Menfiruums, or the Intervention of other Sàline Bodies, it will remain doubtful to a wary perfon, whether the Emergens Salt be that of the Gold it felf; or of the Saline Bodies or Spirits employ'd to prepare it ;

although thoughtful men admitted that both had indirectly helped to provide a great deal of valuable information. Both theories were long regarded as blind spots in a very great mind. But that was before the day of photons and nuclear reactions. Photons are completely respectable and acceptable corpuscles of light now, and gold can be made from mercury by nuclear changes. Newton and his disciples have thus been partly vindicated at last, from unexpected directions and by unpredictable means.

It seems clear that the time has now also arrived to think of gold as a member of the atomic family having just as many relatives as any other, even if it can never be chummy with all of them. It is probably an exaggeration to say that gold is "unknown" in this respect, but not a great exaggeration in relative terms. One has only to look in the compendia of established reactions to see this. The question does not even arise with other well-known elements of ancient lineage, because a great deal more is known about their compounds and capabilities. Now that gold is available in an assured and steady supply through large-scale mining activitiesrather than the old gold rushes and bonanzas-our attitude toward everyday applications by chemical industry must be modernized also. The cost of gold 


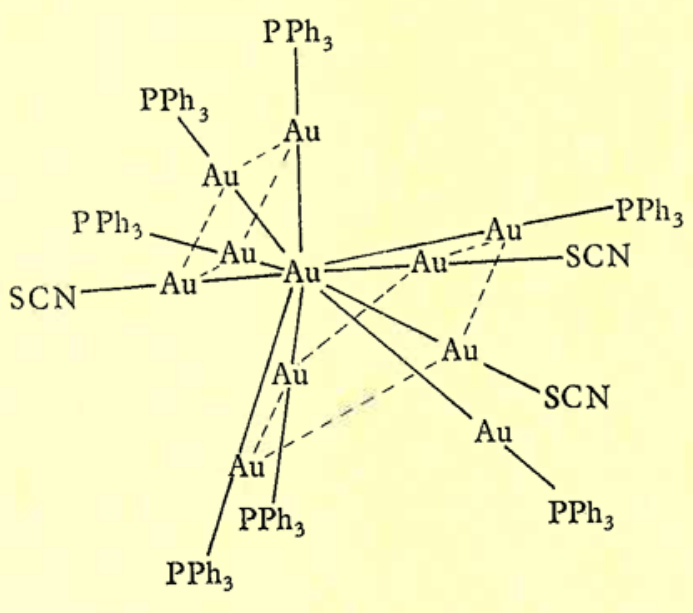

There are many intriguing possibilities that could arise from more intensive studies of the chemistry of gold. This novel cluster complex, for example, one of a number recently synthesised by Professor L. Malatesta and his colleagues at the University of Milan, is believed to have an unusual structure in which a central gold atom is surrounded by ten other gold atoms, each of which has one ligand attached to it

is always a consideration in chemical operations, but never an absolute impediment. Many new industries (in electrical and electronic engineering, for example) have shown how far a very little gold can go to become the cheapest feasible material for a specific purpose. Inertness-so greatly prized when wanted-is similarly no great obstacle to active usefulness. Gold has never been as utterly aloof from its fellows in the atomic family as the noble gases, yet even these truly obdurate elements have lately been persuaded to abandon their primordial exclusiveness enough to interact with common elements for the benefit of all.

The current situation in gold chemistry and some recent advances have been ably summarized by B. F. G. Johnson of Cambridge in the Gold Bulletin for January 1971. Among the most interesting developments from the standpoint of prospective industrial applications are certain series of goldbearing compounds in the organic field. One reason is that similar platinum compounds are important catalysts, and there is good logic in supposing that gold analogues can render a like service for specific purposes. Some of these structures also show promise as reagents for the preparation of organic derivatives.

Gold forms organic compounds in both of its well-established oxidation states, aurous-I and auricIII. Up to very recently, the alkyls constituted nearly the whole story of organic gold (III) com- pounds. The dialkyls are the most stable and the best known organic gold compounds. They remain a most promising group for investigation. Aryl (III) compounds are well-known, but they are not as readily prepared or as well characterised as the alkyls. Exploration here would be rewarding.

Gold acetylide helps to reveal gold's basic relationship with copper and silver, the other members of its triad in the Periodic Table. The acetylides of all three are explosive and dangerous even when kept moist. (These compounds must not be confused with fulminating gold, an inorganic gold-nitrogen molecule which does not become dangerously unstable until dry.) However, in most of its other chemical conduct, gold displays a much closer kinship to the platinum group than to the more-plentiful plebeian elements with which it is associated in the Periodic Table. Gold is the noblest metal in Nature, which is to say that its ions in solution can expect to receive electrons from any other metal, even from noble platinum, to resume the metallic state. In the toning of photographic prints with the sodium salt of chlorauric acid, the grains of silver become coated with gold and are thereby changed from black to an attractive purplish-brown colour. Gold compounds having either characteristic oxidation state are easily reduced to metal. This facility is demonstrated in the generation of beautiful colloidal sols-red, blue or purple, depending on the particle size. The famous Purple of Cassius, which has been used as a delicate test for the presence of gold for ages, has also served for the preparation of stained glass.

New compounds containing gold-to-metal bonds have received recent attention. Gold may here be joined to common metals or to other gold atoms, often in large and complicated organic molecules. Such compounds are of current interest owing to the strong catalytic powers exhibited by similar structures without gold, analogy still supplying some of the most fruitful hints in chemical investigations. Some new activity is seen in the inorganic field though probably less than in organic studies. Oxides, hydroxides, and halogen compounds of gold have been known for many years, mostly as prepared by indirect means. Some mundane work for gold that was formerly shunned is now wisely accepted as a matter of course. For example, sulphuric acid solutions containing gold along with other precious metals are used to activate plastic surfaces prior to plating operations. Additives to lubricating oils, which form a thin deposit of gold on bearing surfaces, have been proposed, but such compounds are likely to be organic. Enough new investigations, whether organic or inorganic, are being reported to indicate that some chemists are endeavouring to correct their long neglect of gold chemistry. 